\title{
Accounting for inventory data and methodological choice uncertainty in a comparative life cycle assessment: the case of integrated multi-trophic aquaculture in an offshore Mediterranean enterprise
}

\author{
Angelica Mendoza Beltran ${ }^{1}$ (D) Mariachiara Chiantore $^{2}$ - Danilo Pecorino ${ }^{2,3}$. \\ Richard A. Corner ${ }^{4}$ • Joao G. Ferreira ${ }^{5} \cdot$ Roberto Cò $^{6} \cdot$ Luca Fanciulli $^{6}$ • \\ Jeroen B. Guinée ${ }^{1}$
}

Received: 24 February 2017 / Accepted: 20 June 2017 / Published online: 10 July 2017

(C) The Author(s) 2017. This article is an open access publication

\begin{abstract}
Purpose Integrated multi-trophic aquaculture (IMTA), growing different species in the same space, is a technology that may help manage the environmental impacts of coastal aquaculture. Nutrient discharges to seawater from monoculture aquaculture are conceptually minimized in IMTA, while expanding the farm economic base. In this study, we investigate the environmental trade-offs for a small-to-medium enterprise (SME) considering a shift from monoculture towards IMTA production of marine fish.

Methods A comparative life cycle assessment (LCA), including uncertainty analysis, was implemented for an aquaculture
\end{abstract}

Responsible editor: Patrik John Gustav Henriksson

Electronic supplementary material The online version of this article (doi:10.1007/s11367-017-1363-2) contains supplementary material, which is available to authorized users.

Angelica Mendoza Beltran

mendoza@cml.leidenuniv.nl

1 Institute of Environmental Sciences (CML), Department of Industrial Ecology, Leiden University, Einsteinweg 2, 2333

CC Leiden, The Netherlands

2 Department of Earth, Environment and Life Sciences (DISTAV), University of Genoa, Corso Europa 26, 16132 Genoa, Italy

3 Evodevo Srl, Via dei Castelli Romani 12/A, Pomezia, 00071 Rome, Italy

4 Longline Environment Ltd, 88 Wood Street, London EC2V 7RS, UK

5 DCEA, Fac. Ciencias e Tecnologia, Universidade Nova de Lisboa, Qta Torre, 2829-516 Monte de Caparica, Portugal

6 Aqua Soc. Agr. s.r.1., Calata Porto Turistico 129, 16033 Lavagna, Italy
SME in Italy. Quantification and simultaneous propagation of uncertainty of inventory data and uncertainty due to the choice of allocation method were combined with dependent sampling to account for relative uncertainties and statistical testing and interpretation to understand the uncertainty analysis results. Monte Carlo simulations were used as a propagation method. The environmental impacts per kilo of fish produced in monoculture and in IMTA were compared. Twelve impact categories were considered. The comparison is first made excluding uncertainty (deterministic LCA) and then accounting for uncertainties.

Results and discussion Deterministic LCA results evidence marginal differences between the impacts of IMTA and monoculture fish production. IMTA performs better on all impacts studied. However, statistical testing and interpretation of the uncertainty analysis results showed that only mean impacts for climate change are significantly different for both productive systems, favoring IMTA. For the case study, technical variables such as scales of production of the species from different trophic levels, their integration (space and time), and the choice of species determine the trade-offs. Also, LCA methodological choices such as that for an allocation method and the treatment of relative uncertainties were determinant in the comparison of environmental trade-offs.

Conclusions The case study showed that environmental trade-offs between monoculture and IMTA fish production depend on technical variables and methodological choices. The combination of statistical methods to quantify, propagate, and interpret uncertainty was successfully tested. This approach supports more robust environmental trade-off assessments between alternatives in LCAs with uncertainty analysis by adding information on the significance of results. It was difficult to establish whether IMTA does bring benefits given 
the scales of production in the case study. We recommend that the methodology defined here is applied to fully industrialized IMTA systems or bay-scale environments, to provide more robust conclusions about the environmental benefits of this aquaculture type in Europe.

Keywords Aquaculture - IMTA · LCA · Offshore mariculture $\cdot$ SME $\cdot$ Uncertainty

\section{Introduction}

Marine aquaculture is not a zero waste activity and can be problematic, with increased organic nutrient loads around farms (Granada et al. 2015), in extremis potentially leading to eutrophication, algae blooms (Chopin et al. 2007) plus seabed impacts, for example. Marine culture of fish is an open production system, and during fish growth, nutrients from excess and uneaten feed and metabolic products, such as feces and urine, are released to the sea. To mitigate some of these issues, integrated multi-trophic aquaculture (IMTA) (Chopin et al. 2001; Reid et al. 2009; Price and Morris 2013) is a practice that could offset environmental impact and help with the management of coastal ocean aquaculture. In open water systems, IMTA typically involves production of a hightrophic-level species of finfish around which lower-trophiclevel species of bivalves and/or seaweed are cultured (Buschmann et al. 2001; Troell et al. 2003). Other combinations of finfish or crustaceans with any filter-feeding organism are also possible (Klinger and Naylor 2012; Cubillo et al. 2016). IMTA offers the possibility of bioremediation for nutrient discharges while broadening the economic base of aquaculture farms by means of product diversification (Granada et al. 2015).

Research to understand the environmental benefits of IMTA has taken place (Abreu et al. 2009; Reid et al. 2009; Klinger and Naylor 2012) for ponds, tanks, and land-based and marine-based setups (Buschmann et al. 2001; Troell et al. 2003), generally at experimental scales or through mathematical modeling (Ferreira et al. 2012; Cubillo et al. 2016). Assessments focus on the productivity effects of coculturing species at different trophic levels, as well as the potential of nutrient uptake or waste discharge reduction by the different species mix. IMTA is potentially useful to eliminate waste and increase the productivity of the food production system (Troell et al. 2003), while increasing the economic and environmental performances of an industry or business (Neori et al. 2004; Hughes and Black 2016). IMTA can, therefore, be considered in terms of eco-intensification, where the productivity per unit input is increased (Amano and Ebihara 2005). What is lacking, however, is a better understanding of the environmental benefits of IMTA at industrial scales of production from a life cycle perspective.
Life cycle assessment (LCA) has been extensively applied to aquaculture and fishery systems (Henriksson et al. 2012; Vázquez-Rowe et al. 2012; Ziegler et al. 2016). LCA of aquaculture typically compares different techniques for production of one species and/or assesses "hot spots" or main contributing activities to the total impact of production of one species (Henriksson et al. 2012; Ziegler et al. 2016). Identifying problem shifting, for instance, the environmental impacts of the effect of feeding wild caught fish to the farmed fish or of using agricultural products to feed the fish (Pelletier and Tyedmers 2008), as well as identifying environmental trade-offs among alternatives (e.g., Henriksson et al. 2015b), is two of the strongest aspects of LCA applied to aquaculture systems.

Despite the usefulness of LCA to identify hot spots and trade-offs of aquaculture production technologies, there are various limitations to its application. One of the key challenges (see Ziegler et al. 2016 for more challenges) is the necessity to go beyond point value estimates and to incorporate uncertainty in the calculations to produce more robust outcomes. Uncertainty appears in many forms in LCA (Björklund 2002), and in aquaculture LCAs, for instance, it is present in inventory data, due to methodological choices, and in impact assessment methods (Ziegler et al. 2016). Two of these sources of uncertainty are expected to play a more determinant role in the impacts of IMTA, namely variability in the production data due to, for instance, unpredictable events such as storms or disease outbreaks and uncertainty due to the choice of allocation method because of the co-production of species in one site.

A critical question for IMTA is what are the environmental trade-offs for a small (or medium) enterprise (small-to-medium enterprise (SME)) considering in shifting its monoculture aquaculture practice towards IMTA. For this study, there was a need to (1) understand what are the environmental trade-offs for a selected SME adopting IMTA and (2) test a method for comparative LCAs with uncertainty analysis, dependent sampling, and statistical testing, as proposed by Henriksson et al. (2015a), while integrating the method outlined in Mendoza Beltran et al. (2015) to propagate the uncertainty due to the choice of allocation method and inventory data simultaneously. Thus, this study has a double aim: to assess the environmental trade-offs for SMEs adopting IMTA, using an Italian SME who has a fish farm site and has been experimenting with fish/shellfish IMTA as a means to increase eco-efficiency, and to assess a proposed method for comparative LCAs with uncertainty analysis. The application of LCA to aquaculture has been growing, but to our knowledge, it has been applied only once (Czyrnek-Delêtre et al. 2017) to IMTA systems for comparative purposes, but not while simultaneously dealing with two uncertainty sources (from here on referred to as uncertainties). Czyrnek-Delêtre et al. (2017) assess the implication of some modeling parameters via sensitivity scenarios but do not assess the effect of methodological choices such 
as allocation and in addition assess an IMTA setup with seaweed and salmon.

\section{Methods}

\subsection{LCA goal and scope}

The goal of this LCA is to quantify the life cycle environmental impacts of the monoculture production of sea bass (Dicentrarchus labrax) and sea bream (Sparus aurata) per kilo of whole boxed and gutted packed finfish and compare them to those of the production of the same fish in an IMTA setup. We study both productive systems for Aqua Soc. Agr. s.r.l., which is a SME with a fish production site located in the Ligurian Sea near Genoa, Italy, and which uses submersible cages to produce mixed cohorts of both fish species. In the analysis, the total number of fish, from both species, is considered as the total production by the farm, without distinguishing between species. The total production is further packed or processed onsite in two final products: the first is whole boxed fish and the second is gutted head-on packed sealed fish (from here on referred to as gutted packed fish). Both products are available at the farm gate. About $4 \%$ of total production per year is gutted on site; before being packed sealed for local distribution, the rest is packed whole with ice in polystyrene boxes, also for local distribution. In a recent demonstration pilot study, the company introduced Pacific oyster (Crassostrea gigas) grown in lantern nets (see the glossary in the supporting information for some aquaculture terms) in proximity to the fish cages, under a concession of the site license, to assess whether this fish/shellfish IMTA system could be successful in reducing finfish impacts and enable the company to diversify product lines. LCA was used to compare the impacts between fish produced in monoculture and IMTA systems. The functional unit is the same for both systems: $1 \mathrm{~kg}$ of whole boxed fish and gutted packed fish at farm gate. From this kilo, $0.04 \mathrm{~kg}$ corresponds to gutted packed fish and $0.96 \mathrm{~kg}$ to whole boxed fish. Any processes performed after the farm gate, including fish retail and human fish consumption, is equivalent in both systems.

\subsubsection{Monoculture and IMTA systems}

Produced fish are humanely killed at harvest, processed, and packed as explained. Flows and system boundaries of the monoculture system were defined after consultation with the SME (Fig. 1a) and consist of eight sub-systems: fry (juvenile fish) production and transport to farm (S1), infrastructure construction consisting of offshore and onshore infrastructure (S2), feed production (S3), feed transport to farm (S4), maintenance of the farm (S5), growth (S6), harvest (S7), and processing of the fish (S8). The farm feed conversion ratio (FCR) oscillates depending on the size of the fish and time of year but is a mean of 2.8 , meaning that $2.8 \mathrm{~kg}$ of feed is required to produce $1 \mathrm{~kg}$ of fish.

There are almost no changes required to the fish monoculture site with the introduction of the oysters. Therefore, for the LCA of the IMTA system, the monoculture system is the same and the introduction of oysters was considered as an add-on called "IMTA sub-system" (Fig. 1b). Various tests were carried out to define an appropriate layout at the site, but the selected design in the IMTA sub-system consisted of longlines attached to the existing fish cage mooring system to the north and south, in line with the water flows through the site, with lantern nets used to contain oysters while they underwent growth (see Fig. S.1 in the Electronic Supplementary Material for farm layout). The introduction of the IMTA sub-system resulted in additional processes, some of which were integrated within one or other of the eight monoculture sub-systems. These processes included oyster seed production, oyster seed transport to farm, construction of the IMTA infrastructure (integrated in S2), seed transport to lantern nets, management and grow-out of oysters (integrated with S6), and maintenance of the IMTA sub-system (integrated in S5). During the pilot, oysters were grown for 12 months on site to a degree in which they were ready for retail; however, it is expected that in the industrial IMTA production, transport of oysters to a different location for final fattening and conditioning could be required. Oyster fattening and conditioning are not included in this analysis. The farm gate for the LCA for the IMTA system was at the point where fish are ready for retail and oysters are ready for conditioning.

\subsection{Inventory}

The inventory description provided here for both systems focuses on stochastic inputs calculated via horizontal averaging of primary and secondary data (Henriksson et al. 2014). Details about other inventory data flows for foreground and background processes of both systems considered, their collection, and implementation in the LCA software are provided in the supporting information. For all calculations, the CMLCA software version beta 5.2 was used. Full inventory tables for both systems are also provided in the supporting information. Data were collected over a full growth cycle for the fish component of the IMTA system, being 22 months, and encompassed two production cycles of 12 months for the oysters, after which all data were standardized to 1 year.

\subsubsection{Foreground data}

Foreground inventory data collection (see gray boxes in Fig. 1) took place in two steps: (1) for the monoculture system and (2) for the IMTA sub-system, which was subsequently integrated with the monoculture. 
(a)

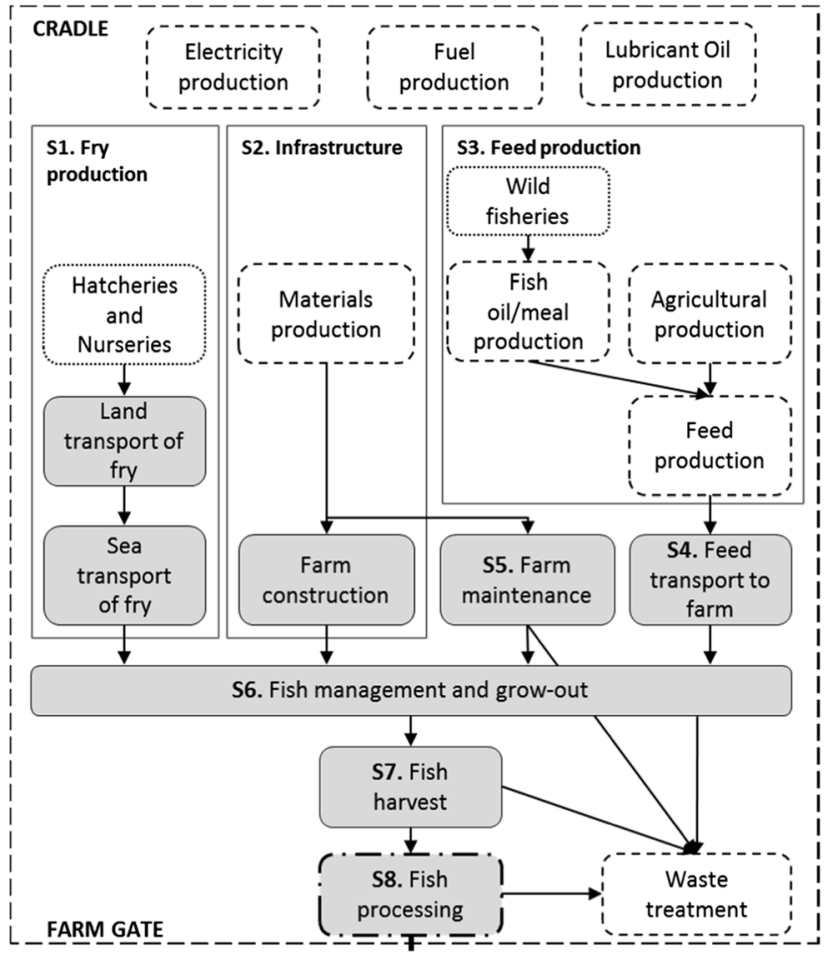

Whole boxed and gutted packed fish at farm gate

(b)

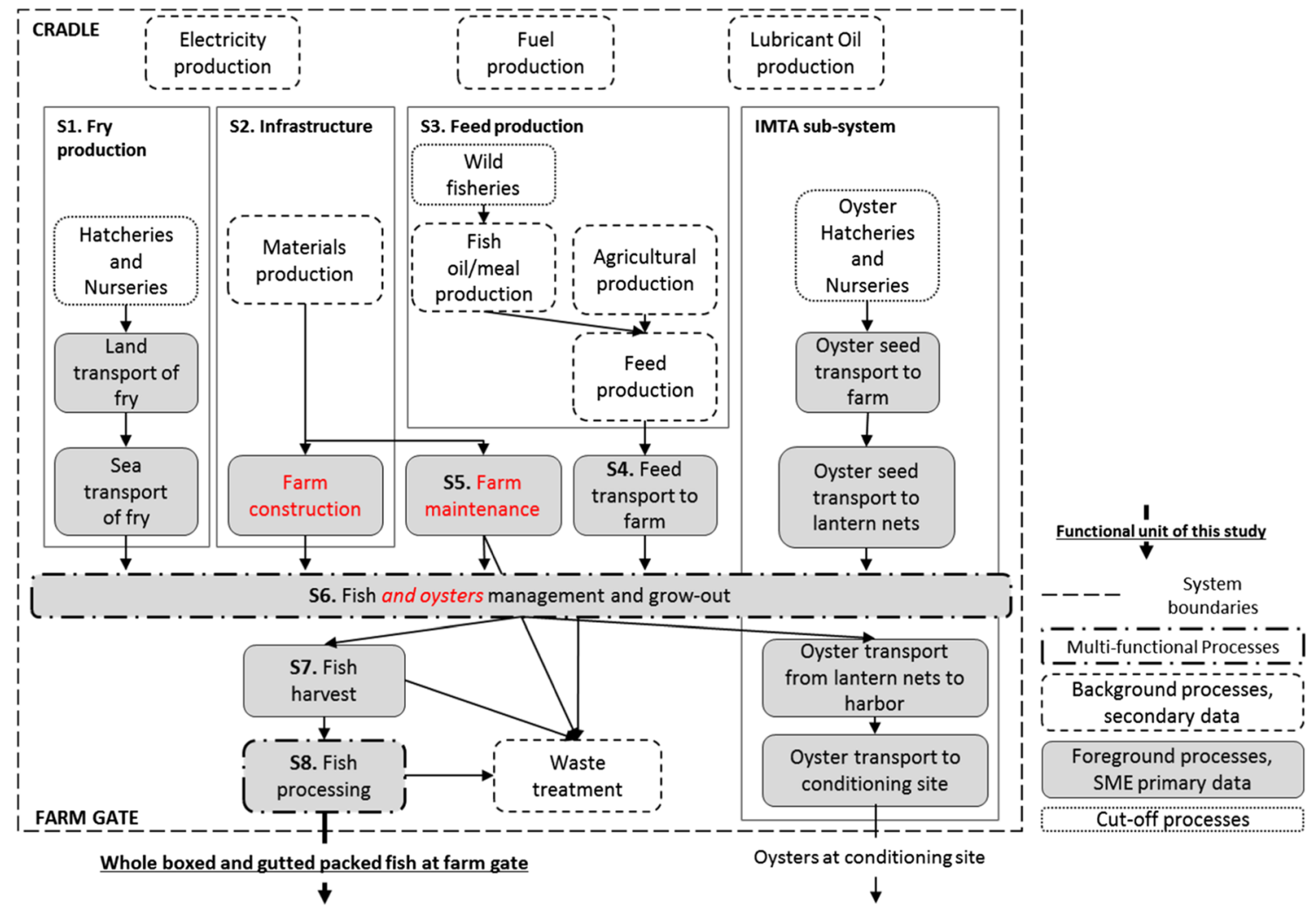


Fig. 1 Flow diagrams of a the monoculture (mono) system and $\mathbf{b}$ the integrated multi-trophic aquaculture (IMTA) system. Gray boxes represent the foreground processes for which primary data were collected, and white boxes represent background processes for which secondary data were used. Processes highlighted in red are processes that changed in the IMTA system compared to the monoculture system due to introduction the oyster add-on

For the monoculture inventory, production data were collected over the period 2012 to 2014 (Table 1) and used as a basis for estimating the stochastic inputs for the inventory of fish management and grow-out and fish processing. Following Henriksson et al. (2014), the data for the 3 years was horizontally averaged (Table 1) leading to weighted averages, lognormal distributions, and an overall dispersion parameter Phi, used in the LCA software (Heijungs and Frischknecht 2005). Inherent uncertainties due to measurement or calculation imprecision are estimated using basic uncertainties (Henriksson et al. 2014) for semi-finished products (Frischknecht et al. 2007), and data representativeness for the case study and spread due to variability in the yearly production were reflected from the 3-year production data and their representativeness for the case. Data for other foreground processes (including fuel use by boats, major onshore and offshore infrastructure including the production of component materials, chemicals use, and so on) were collected for the 2012 fish production cycle and standardized to 1 year. Data were presented as point values per year without uncertainty estimates. Therefore, for the deterministic LCA calculations (excluding uncertainties), point values and the weighted averages for flows with stochastic estimates were used as the foreground inventory. For the uncertainty calculations, the stochastic inputs for fish growth and fish processing with point values for the rest of the foreground inventory were used. For fish growth, an important flow that does not include uncertainty estimates is mortality of fish. Mortality is considered to be any reason for fish loss from the farm and includes losses from disease, which can be assessed, and escapees which cannot be assessed until after the harvest is completed and fish counted. Overall mortality was $30 \%$ of the fry seeded in 2012 , due almost exclusively to escapees (Table 1). Fish loss is reported as an emission to marine water, but it is not classified in any specific impact.

Under IMTA, it was assumed that there were two sub-systems: the monoculture sub-system, for which data corresponded to that described above except for a few adaptations required (i.e., red processes in Fig. 1b), and the IMTA sub-system for which IMTA pilot-scale data were collected and further up-scaled. Foreground data were collected for oysters grown on site for 1 year (2014-2015) at an initial pilot scale of production. During the pilot, around 1400 individual oysters were delivered to site and cultivated in three lantern nets (with 10 layers and 45-cm diameter) placed west of the farm, downstream relative to the main flow from the fish cages. Data for infrastructure, grow-out, maintenance, harvest, and transport of the oysters were collected. In the pilot, oysters reached an average shell-on wet weight of $68 \mathrm{~g}$. Mortality was

Table 1 Monoculture production data for 2012, 2013, and 2014 including both sea bream and sea bass for our case SME

\begin{tabular}{|c|c|c|c|c|c|c|}
\hline Unit process & $\begin{array}{l}\text { Input/output [NUSAP scores (Weidema and } \\
\text { Wesnæs 1996)] }\end{array}$ & Unit & 2012 & 2013 & 2014 & $\begin{array}{l}\text { Protocol (Henriksson } \\
\text { et al. 2014) }\end{array}$ \\
\hline \multirow[t]{6}{*}{ Fish growth } & Inputs & & & & & \\
\hline & Fry, at cages $[3,1,1,1,1,4]$ & fry/year & 850,000 & 940,000 & $1,045,000$ & $945,000[\mathrm{~L}(0.134)]$ \\
\hline & Fish feed, at farm $[1,1,1,1,1,4]$ & $\mathrm{kg} /$ year & 589,000 & 719,050 & 841,750 & $717,000[\mathrm{~L}(0.189)]$ \\
\hline & Outputs & & & & & \\
\hline & Grown life at farm ${ }^{\mathrm{b}}[3,1,1,1,1,4]$ & $\mathrm{kg} /$ year & 240,000 & 223,328 & 295,776 & $253,000[\mathrm{~L}(0.172)]$ \\
\hline & Mortality & $\mathrm{kg} /$ year & 255,000 & n.c. & n.c. & 255,000 \\
\hline \multirow[t]{4}{*}{ Fish processing } & Outputs & & & & & \\
\hline & Whole boxed fish at plant $[1,1,1,1,1,4]$ & $\mathrm{kg} /$ year & 230,400 & 214,760 & 281,700 & $242,000[\mathrm{~L}(0.16)]$ \\
\hline & Gutted packed fish at plant $[1,1,1,1,1,4]$ & $\mathrm{kg} /$ year & 8400 & 7450 & 12,240 & $9360[\mathrm{~L}(0.275)]$ \\
\hline & Fish guts at plant ${ }^{\mathrm{c}}[3,1,1,1,1,4]$ & $\mathrm{kg} /$ year & 1200 & 1117.5 & 1836 & $1380[\mathrm{~L}(0.291)]$ \\
\hline
\end{tabular}

n.c. not calculated; fish were still located in cages and mortality can only be measured after harvest

${ }^{a}$ The results of the horizontal averaging protocol from Henriksson et al. (2014) correspond to weighted means for the 3-year data, as well as lognormal distribution [L] and an overall dispersion parameter Phi (in parenthesis)

${ }^{\mathrm{b}}$ Calculated as the sum of whole boxed fish, gutted fish, and guts

${ }^{\mathrm{c}}$ Calculated as the $15 \%$ of the weight of gutted fish 
$20 \%$ of the oysters seeded. These pilot data from the IMTA sub-system were up-scaled to a more representative industrial level of production for the LCA assessment, based on a linear extrapolation with expert assessment. Experts confirmed the plausibility of these data as a good average representation of the oyster add-on despite of the different configurations between the pilot and the considered up-scaled IMTA system. It was assumed that the same oyster growth behavior, mortality, and managing activities, developed under the pilot, apply to the industrial-scale IMTA sub-system. Oyster seed input at the industrial scale was 77,000 individuals based on the stocking density per lantern determined through the pilot study (around 480 individual oysters per lantern net) and the projected use of 160 lantern nets. Assuming the growth of oysters under the pilot, the yearly production of oysters at the industrial-scale IMTA system was calculated to be approximately $4.2 \mathrm{t}$ shellon wet weight (Eq. (1)).

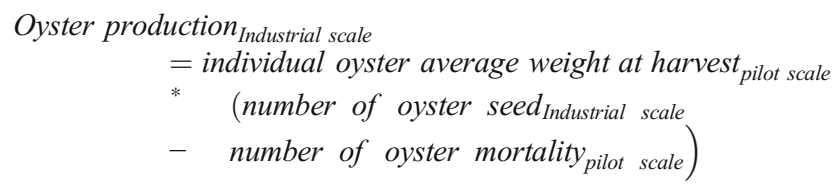

For the analysis, oyster growth was considered to be an integrated part of fish production (S6), and therefore, the grow-out and management process in the monoculture systems (Fig. 1a) becomes a multi-functional process growing both fish and oysters in the IMTA system (Fig. 1b). Other data on foreground processes of the IMTA sub-system (including transport, additional maintenance, and infrastructure) were collected for the pilot scale and up-scaled to the industrial production scale and integrated in the farm construction process (S2) and farm maintenance process (S5, see supporting information for details). These data correspond to point values per year without uncertainty estimates as these were not available.

A key inventory flow for both systems is the net emission of particulate and dissolved nutrients to the sea during the cultivation period. Carbon emissions are not included as these mostly lead to carbon enrichment of the benthic layer. This is an impact rarely accounted for in aquaculture LCAs given the recent development of this impact within the LCA framework (Langlois et al. 2015). In this study, we focused on nitrogen and phosphorus emissions because of their potential to cause environmental damage in aquatic environments and their accountability in LCA impact categories such as eutrophication. In the monoculture system, fish were fed a pelleted feed and, when ready, they were harvested at the end of the production cycle, thus removing some added nutrients as harvestable product. Losses to the environment consisted of excretory products from fish metabolism (urine and feces) and uneaten feed. Under the IMTA system, emissions from the fish component were the same as those under monoculture, with no impact of co-cultivation on fish growth. Oysters remove phytoplankton and other detritus from the water column, convert this to tissue growth, and emit both phosphorus and nitrogen in particulate waste and through nitrogen excretion. There is no direct consideration of a coupling between fish wastes being taken up by the oysters, simply the net change when both species are grown in the same space, although it is likely that at least a part of the detrital material ingested by the oysters will contain fish feed waste and fecal material (Reid et al. 2013).

Emissions were predicted using the Farm Aquaculture Resource Management (FARM) model (Ferreira et al. 2012; Cubillo et al. 2016) for the fish component (monoculture system) and for the fish and oyster component run simultaneously (IMTA system) to define the net emissions. Setup of the FARM model is described by Cubillo et al. (2016), and model runs were completed using environmental driver data collected at the SME farm and based on the culture practices used (e.g., stocking density, seed, harvest weights, and cultivation period). FARM models the outputs generated by species growth processes as nitrogen and phosphorus emissions to sea water, used as the inventory data for the monoculture system, being $62.4 \mathrm{t} \mathrm{N}_{\text {year }}{ }^{-1}$ and $2.4 \mathrm{t} \mathrm{P} \mathrm{year}^{-1}$. For the IMTA system, the inventory data are the net nutrient emissions from fish growth minus the net nutrient uptake by oysters $\left(0.1152 \mathrm{t} \mathrm{N}\right.$ year $^{-1}$ and $0.0091 \mathrm{t} \mathrm{P}$ year $\left.^{-1}\right)$, thus being $62.285 \mathrm{t} \mathrm{N}$ year $^{-1}$ and $2.391 \mathrm{t} \mathrm{P}$ year $^{-1}$. The FARM model reports outputs in kilogram per year, converted to tons per year $^{-1}$ to retain the same units throughout.

\subsubsection{Background data}

Background data for monoculture and IMTA fish production correspond to the sub-systems outlined in Fig. 1. Each foreground flow is linked to background processes from the ecoinvent V2.2 database (Swiss Centre For Life Cycle Inventories 2007) for most inputs. The exception was the feed production sub-system where horizontal averaging (Henriksson et al. 2014) of various secondary sources for the feed mills (see supporting information) and data from the SEAT project (Henriksson et al. 2015b) for agricultural and capture fisheries were used. Ecoinvent v2.2. includes uncertainty estimates based on the NUSAP pedigree scores (Weidema and Wesnæs 1996), and despite this not being the most optimal quantification of uncertainty for background processes, it was the best available information.

\subsubsection{Allocation}

Multi-functionality takes place in two foreground processes of the IMTA system: (1) the fish and oyster management and grow-out and (2) the fish processing (also part of the 
Table 2 Allocation factors used for the SME monoculture and IMTA systems

\begin{tabular}{|c|c|c|c|c|}
\hline Multi-functional process & Partitioning principle & Co-product & $\begin{array}{l}\text { Partitioning } \\
\text { factor }\end{array}$ & $\begin{array}{l}\text { Mendoza Beltran et al. (2015) } \\
\text { Methodological preference }\end{array}$ \\
\hline \multirow[t]{4}{*}{ Fish processing ${ }^{a}$} & \multirow[t]{2}{*}{ Mass partitioning } & $\begin{array}{l}\text { Whole boxed fish } \\
\text { Gutted fish }\end{array}$ & $\begin{array}{l}0.958 \\
0.037\end{array}$ & \multirow[t]{2}{*}{50} \\
\hline & & Guts & 0.005 & \\
\hline & \multirow[t]{2}{*}{ Mass-adjusted economic allocation } & $\begin{array}{l}\text { Whole boxed fish } \\
\text { Gutted fish }\end{array}$ & $\begin{array}{l}0.95 \\
0.05\end{array}$ & \multirow[t]{2}{*}{50} \\
\hline & & Guts & 0 & \\
\hline \multirow[t]{3}{*}{$\begin{array}{l}\text { Fish and oyster management } \\
\text { and grow-out }{ }^{\mathrm{b}}\end{array}$} & Mass partitioning & $\begin{array}{l}\text { Sea bass and sea bream at cages } \\
\text { Oysters at lanterns }\end{array}$ & $\begin{array}{l}0.98 \\
0.02\end{array}$ & 50 \\
\hline & Mass-adjusted economic allocation & $\begin{array}{l}\text { Sea bass and sea bream at cages } \\
\text { Oysters at lanterns }\end{array}$ & $\begin{array}{l}0.992 \\
0.008\end{array}$ & 50 \\
\hline & Protein content ${ }^{\mathrm{c}}$ & $\begin{array}{l}\text { Sea bass and sea bream at cages } \\
\text { Oysters at lanterns }\end{array}$ & $\begin{array}{l}0.99 \\
0.01\end{array}$ & - \\
\hline
\end{tabular}

${ }^{a}$ Applied in both monoculture and IMTA systems

${ }^{\mathrm{b}}$ Applied in IMTA system only

${ }^{\mathrm{c}}$ Protein content partitioning was not considered as a physical allocation principle as the allocation factors are very similar to those of economic allocation, but it is shown here for indication

monoculture system). According to the International Organization for Standardization 14044 guidelines, the allocation method choice involves a stepwise procedure (ISO 2006), being to (1a) avoid allocation by dividing multifunctional unit processes, (1b) avoid allocation by expanding the system, (2) divide the system (partitioning) using physical relations between products, and (3) divide the system (partitioning) by other product relations. During the data collection for both systems, it became evident that avoiding allocation for the grow-out process in the IMTA system was not possible, as this process will simultaneously grow fish and oysters, making it difficult to allocate inputs and outputs of this joint activity to individual processes for each species. System expansion was similar, and no data were available for the monoculture system expansion to include the "monoculture" production of oysters in a similar location with a similar technology. Substitution was also not possible as the substituted products resulting from oyster production could not be determined. Therefore, allocation based on partitioning was applied in both processes. For the deterministic LCA results, mass-adjusted economic allocation (from here on referred as economic allocation) and mass partitioning were used in both processes. When uncertainty was included, we applied the pseudo-statistical method described by Mendoza Beltran et al. (2015). This method uses the so-called "methodological preference" per partitioning method to propagate choice uncertainty simultaneously with inventory data uncertainty to the LCA results. Table 2 describes the principles, allocation factors used, and the methodological preference applied to each partitioning method, which corresponds to equal preference. In both type of calculations, i.e., the deterministic and the uncertainty LCA calculations, all environmental flows are allocated between the fish and the oysters. For background multi-functional processes, we use the allocation defined in ecoinvent 2.2 and mass allocation for the processes derived from the SEAT project. The pseudo-statistical method to propagate uncertainty due to the choice of allocation method is therefore not applied to multifunctional processes in the background.

\subsection{Life cycle impact assessment}

Impacts were considered at the midpoint level. Characterization factors and impact categories were implemented according to the CML-IA database (CMLDepartment of Industrial Ecology 2016). The impact categories used were abiotic resource depletion-elements, abiotic resource depletion - fossil fuels, global warming for a 100year time horizon, (stratospheric) ozone depletion, human toxicity, photochemical oxidation, acidification (land and water), and eutrophication (land and water). Ecotoxicity for marine ecosystems has not been included as an impact category, following advice in the Declaration of Apeldoorn (UNEP/SETAC Life Cycle Initiative 2004). We also considered four additional categories from other sources: human toxicity and freshwater ecotoxicity according to the USEtox model (Rosenbaum et al. 2008). For freshwater use, the "blue water footprint" concept (Mekonnen and Hoekstra 2011) was applied. Where freshwater is required to supply the functional unit throughout the supply chain, use is accounted for, although no explicit reference to specific water sources is made. For land use, physical land occupation data $\left(\mathrm{m}^{2}\right)$ were added without specific characterization factors (or in other words 
was equal to one), for each process of the value chains analyzed. Finally, no normalization or weighting was undertaken.

\subsection{Interpretation}

\subsubsection{Uncertainty analysis}

Using the stochastic inventory data for the foreground and background processes of both systems, and the equal methodological preference for allocation methods in both systems, we simulated 1000 Monte Carlo (MC) runs to propagate these uncertainties to the characterized LCA results per impact category per alternative. Relative uncertainties between alternatives are captured by applying two techniques: first, dependent sampling and, second, subtracting the characterization result between both systems for each MC run (Henriksson et al. 2015a). Dependent sampling implies that the characterized results for both systems are based upon the same parameter values randomly drawn in each $\mathrm{MC}$ run for the shared process on the background. Suppose that both the IMTA and the monoculture system share the same electricity production process in their backgrounds. As a result of dependent sampling, the characterized results per MC run for both alternatives are based on the same parameter values for electricity production. In fact, the full technology matrix and the environmental extensions matrix are equal for both alternatives in each $\mathrm{MC}$ run. Subtracting the characterization result for IMTA from that of the monoculture system for each MC run serves to account for the comparative difference between the systems. Failing to look at the difference between systems, for instance, by comparing the distribution of the $1000 \mathrm{MC}$ runs per alternative, would be like comparing independent results for each alternative, i.e., without accounting for the shared processes on the background. Therefore, for comparative LCAs, dependent sampling with subtraction of results between alternatives is the only relevant option for the purpose of finding the statistical significance of the difference of performance of the alternatives; independent sampling disregards relative uncertainties in comparative LCA and therefore would be pointless for such purpose (Heijungs et al. 2017).

In order to test the significance of the difference of the impacts between both alternatives considered here, a null hypothesis was defined as the fish produced in IMTA and in monoculture systems have equal environmental impacts per kilo of fish. A paired $t$ test was used to determine statistical significance of the difference of environmental impacts between both systems. This method corresponds to the results of the null hypothesis significance testing (NHST) proposed by Henriksson et al. (2015a). The choice for this statistical test has two reasons: (1) the mean difference between the characterized results for IMTA and monoculture follow a normal distribution, according to normality test applied in SPSS v23 (i.e., Kolmogorov-Smirnov and Shapiro-Wilk) except for freshwater ecotoxicity, ozone depletion, human toxicityUSEtox, photochemical oxidation, and water use and (2) the number of runs is large enough (1000 MC runs) to apply a parametric test, as the distribution of means of the difference between the characterized results for IMTA and monoculture will be approximately normally distributed (Agresti and Franklin 2007).

\subsubsection{Other methods for uncertainty statistics of comparative LCAs}

To further understand the environmental trade-offs between fish monoculture and the IMTA system, and to compare outcomes of different interpretation approaches, we also implemented three statistical methods, in addition to NHST, for advanced uncertainty result interpretation in the comparative LCA. They are (1) the overlap area (Prado-Lopez et al. 2016) that shows the common area between the probability distributions of the alternative results (i.e., IMTA and monoculture) per impact, where the closer to one, the more equal the distributions are and the closer to zero, the more separate the distributions are and (2) the discernibility analysis (Heijungs and Kleijn 2001) shows how often in percentage of total MC runs, one alternative has a higher result than the other. A $100 \%$ result means that for all $\mathrm{MC}$ runs, one alternative scores higher than the other. The closer the result to $50 \%$, the more likely the two alternatives are to have the same result, thus the less discernible they are for that impact, and (3) the modified NHST (Heijungs et al. 2016) shows the statistical significance of the null hypothesis in which the results of one alternative are "at least" a certain factor $d_{0}$ different from the results of the other alternatives. Thus, $d_{0}$ is a dimensionless indicator for the acceptable threshold for the difference between the means of the two alternatives (so-called "Cohen's $d$ " as explained by Heijungs et al. 2016). All methods were implemented in a common excel file as described by Mendoza Beltran et al. (2017). ${ }^{1}$

\section{Results}

Figure 2 shows the characterized LCA results for the deterministic calculations per impact category. According to these outcomes (Fig. 2a), the IMTA system generally performs better than the monoculture system for all categories per kilo of fish produced for both allocation methods used. Eutrophication is the impact category showing the highest improvement although not more than about $2 \%$ in the case of mass partitioning allocation. Figure $2 \mathrm{~b}$ shows each subsystem contribution to the total impacts of both alternatives. Almost no difference is observed between both alternatives.

\footnotetext{
${ }^{1}$ Available on request to the corresponding author.
} 


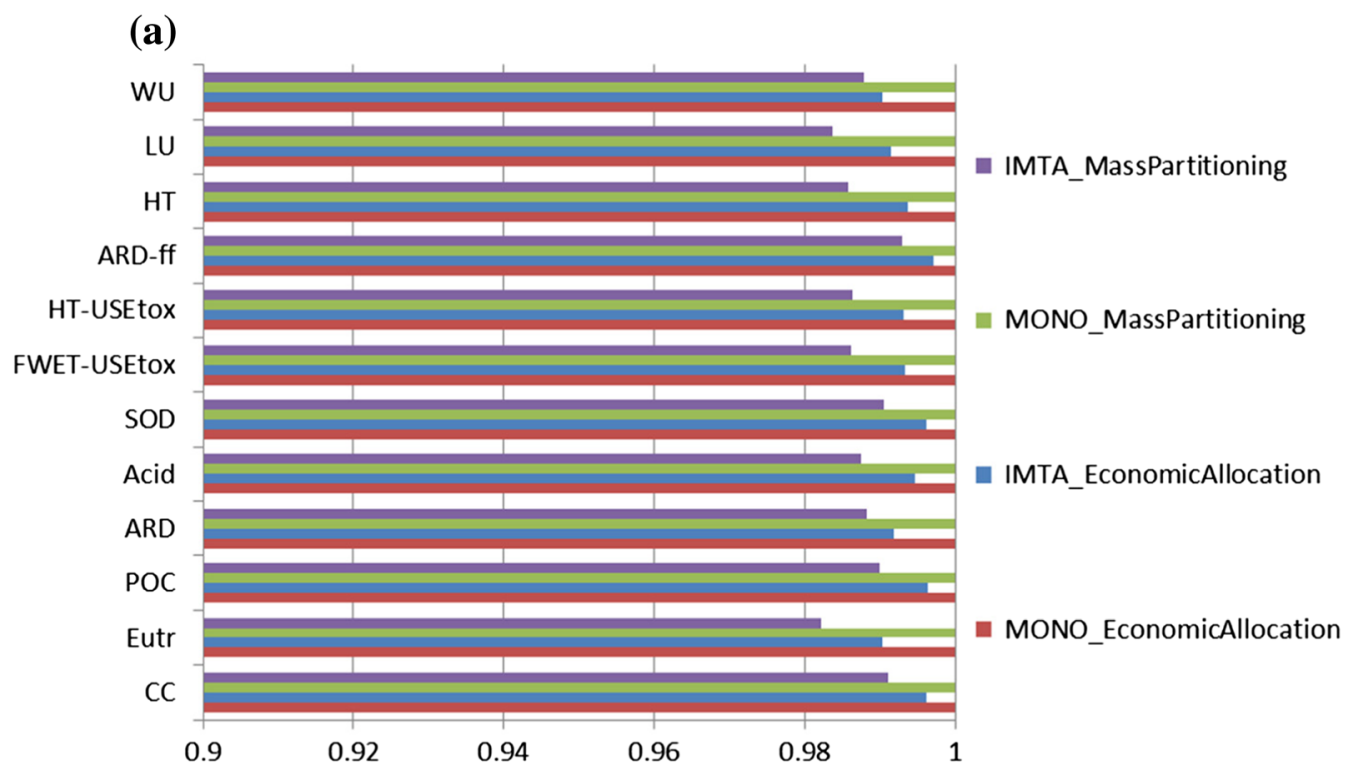

(b)



Fig. 2 a Deterministic LCA results for the IMTA and monoculture alternatives (scaled to the largest results per category) both calculated with economic allocation and mass partitioning for multi-functional processes in the foreground and $\mathbf{b}$ contribution results for both alternatives and sub-systems as described in Fig. 1 and calculated with economic allocation (results are equal for mass partitioning). The impact

categories are climate change (CC), eutrophication (Eutr), photochemical oxidation (POC), abiotic resource depletion - elements (ARD), acidification (Acid), (stratospheric) ozone depletion (SOD), USEtox ecotoxicity - freshwater (FWET-USEtox), USEtox human toxicity (HTUSEtox), abiotic resource depletion - fossil fuels (ARD-ff), human toxicity (HT), Land use (LU) and water use (WU). S1-S8: as shown in Fig. 1

As expected, feed production had the highest impacts for all categories considered except for eutrophication impacts for which the on-site emissions to sea dominate. Also, infrastructure is responsible for about $60 \%$ of the impacts for abiotic resource depletion and plays an important role in human toxicity and freshwater ecotoxicity. These results hold for both types of partitioning considered.

Table 3 compares the deterministic LCA results in Fig. 2a against the outcomes of other uncertainty statistics methods. From left to right, Table 3 first shows the deterministic results, based on point values, in which IMTA impacts are lower for all impact categories considered per fish kilo. Also, the percentage of decrease of impacts in the IMTA system compared to monoculture is shown for the deterministic results. Second, the overlap area shows that the least overlapping categories are climate change and eutrophication, and for the other impacts, the overlap area is about one. Discernibility shows that for almost all impacts, both IMTA and monoculture results are around 0.5 . This indicates that both alternatives are likely to get the same result for all impacts. NHST shows that for all impact categories, LCA results are not significantly different between the two alternatives except for climate change. This impact category is significantly different for fish produced in IMTA and in monoculture. Thus, fish produced in 
Table 3 Results of deterministic LCA and four statistical methods to interpret the uncertainty analysis for the comparison between IMTA and monoculture (mono) produced fish

\begin{tabular}{|c|c|c|c|c|c|c|c|c|}
\hline \multirow{2}{*}{$\begin{array}{l}\text { Impact } \\
\text { category } \\
\text { Criteria } \\
\text { evaluated }\end{array}$} & \multicolumn{3}{|c|}{ Deterministic LCA (point values) } & \multirow{2}{*}{$\begin{array}{l}\text { Overlap area } \\
\text { Overlap of } \\
\text { distributions } \\
\text { (from } 0 \text { to } 1 \text { ) }\end{array}$} & \multicolumn{2}{|l|}{ Discernibility } & \multirow[b]{2}{*}{$\begin{array}{l}\text { NHST } \\
\text { H0: } \\
\text { mono = IMTA } \\
p<0.05=\text { yes } \\
\text { (significantly } \\
\text { different) } \\
p>0.05=\text { no } \\
\text { (not } \\
\text { significantly } \\
\text { different) }\end{array}$} & \multirow[b]{2}{*}{$\begin{array}{l}\text { Modified } \\
\text { NHST } \\
\text { H0: mono- } \\
\text { IMTA <=0.2 } \\
p<0.05=\text { yes } \\
\text { (significantly } \\
\text { different) } \\
p>0.05=\text { no } \\
\text { (not } \\
\text { significantly } \\
\text { different) }\end{array}$} \\
\hline & $\begin{array}{l}\text { Mono > } \\
\text { IMTA } \\
\text { (yes, no) }\end{array}$ & $\begin{array}{l}\text { Percentage } \\
\text { decrease (mono- } \\
\text { IMTA/mono) } \\
\text { economic } \\
\text { partitioning (\%) }\end{array}$ & $\begin{array}{l}\text { Percentage } \\
\text { decrease (mono- } \\
\text { IMTA/mono) } \\
\text { mass partitioning } \\
(\%)\end{array}$ & & $\begin{array}{l}\text { Mono > IMTA } \\
(\% \text { of total MC } \\
\text { runs })(\%)\end{array}$ & $\begin{array}{l}\text { IMTA > mono } \\
(\% \text { of total } \\
\text { MC runs })(\%)\end{array}$ & & \\
\hline Climate change & Yes & 0.4 & 0.9 & 0.96 & 47 & 53 & Yes & No \\
\hline Eutrophication & Yes & 1.0 & 1.8 & 0.96 & 50 & 50 & No & No \\
\hline $\begin{array}{l}\text { Photochemical } \\
\text { oxidation }\end{array}$ & Yes & 0.4 & 1.0 & 0.99 & 50 & 50 & No & No \\
\hline $\begin{array}{l}\text { Abiotic } \\
\text { resource } \\
\text { depletion }\end{array}$ & Yes & 0.8 & 1.2 & 0.98 & 51 & 49 & No & No \\
\hline Acidification & Yes & 0.5 & 1.3 & 0.99 & 48 & 52 & No & No \\
\hline $\begin{array}{l}\text { Ozone } \\
\text { depletion }\end{array}$ & Yes & 0.4 & 1.0 & 0.97 & 50 & 50 & No & No \\
\hline $\begin{array}{l}\text { USEtox } \\
\text { ecotoxicity } \\
\text { freshwater }\end{array}$ & Yes & 0.7 & 1.4 & 0.97 & 49 & 51 & No & No \\
\hline $\begin{array}{l}\text { USEtox human } \\
\text { toxicity }\end{array}$ & Yes & 0.7 & 1.4 & 0.98 & 48 & 52 & No & No \\
\hline $\begin{array}{l}\text { Abiotic } \\
\text { resource } \\
\text { depletion } \\
\text { fossil fuels }\end{array}$ & Yes & 0.3 & 0.7 & 1.00 & 51 & 50 & No & No \\
\hline Human toxicity & Yes & 0.6 & 1.4 & 0.97 & 47 & 53 & No & No \\
\hline Land use & Yes & 0.8 & 1.6 & 0.99 & 50 & 50 & No & No \\
\hline Freshwater use & Yes & 1.0 & 1.2 & 0.99 & 51 & 49 & No & No \\
\hline
\end{tabular}

Each method displays different results according to the evaluated criteria specified on the second row of the table

IMTA leads to lower emissions in $\mathrm{CO}_{2 \text { eq }}$ per fish kilo than monoculture production. Finally, modified NHST results show that no impact, including climate change, is at least $d_{0}=0.2$ significantly different between these two systems. This indicates that despite that the means for climate change are significantly different (according to NHST), they are very close to each other, i.e., less than the threshold of 0.2 units. The chance of finding statistical significance is increased for large sample datasets (such that from simulation models), and modified NHST was proposed as a way to deal with such limitation of significance tests (Heijungs et al. 2016).

\section{Discussion}

We discuss the results in the light of the two aims of this study: to assess the environmental trade-offs for SMEs adopting IMTA and to assess a proposed method for comparative LCAs with uncertainty analysis.

\subsection{Case study}

Monoculture fish production leads to nutrient emissions that are expected to be reduced in IMTA fish production. Deterministic results show that IMTA performs better than monoculture for all impacts per kilo of fish produced and eutrophication is the impact category with the largest improvement. On the other hand, uncertainty results and specifically NHST results showed that impacts are not significantly different for both technologies, except for climate change, which was found to be significantly lower under the IMTA system per kilo of fish produced. In addition, the overlap area between IMTA and monoculture distributions for all impact categories is very close to one, and discernibility results favor IMTA and monoculture each in around 50\% of the cases for all impact categories as well. Therefore, deterministic results are oversimplified outcomes. To further understand the difference between deterministic and uncertainty results, Fig. 3 illustratively presents the histograms for the $\mathrm{MC}$ runs for both 
alternatives for climate change and eutrophication. Deterministic results are based on the mean of the distributions, which is marginally lower for the IMTA system for both impact categories, i.e., $0.4 \%$ for climate change and $1 \%$ for eutrophication. However, there is a larger difference between the means of both alternatives for climate change than for eutrophication (as confirmed by modified NHST results), while the dispersion of the difference between monoculture and IMTA is larger for eutrophication (the quartile coefficient of dispersion (Q3 - Q1/Q3 + Q1) of eutrophication is 2.1 times larger than for climate change). The bottom panels of Fig. 3 show the difference between monoculture and IMTA per MC run for both impact categories. The top panels of
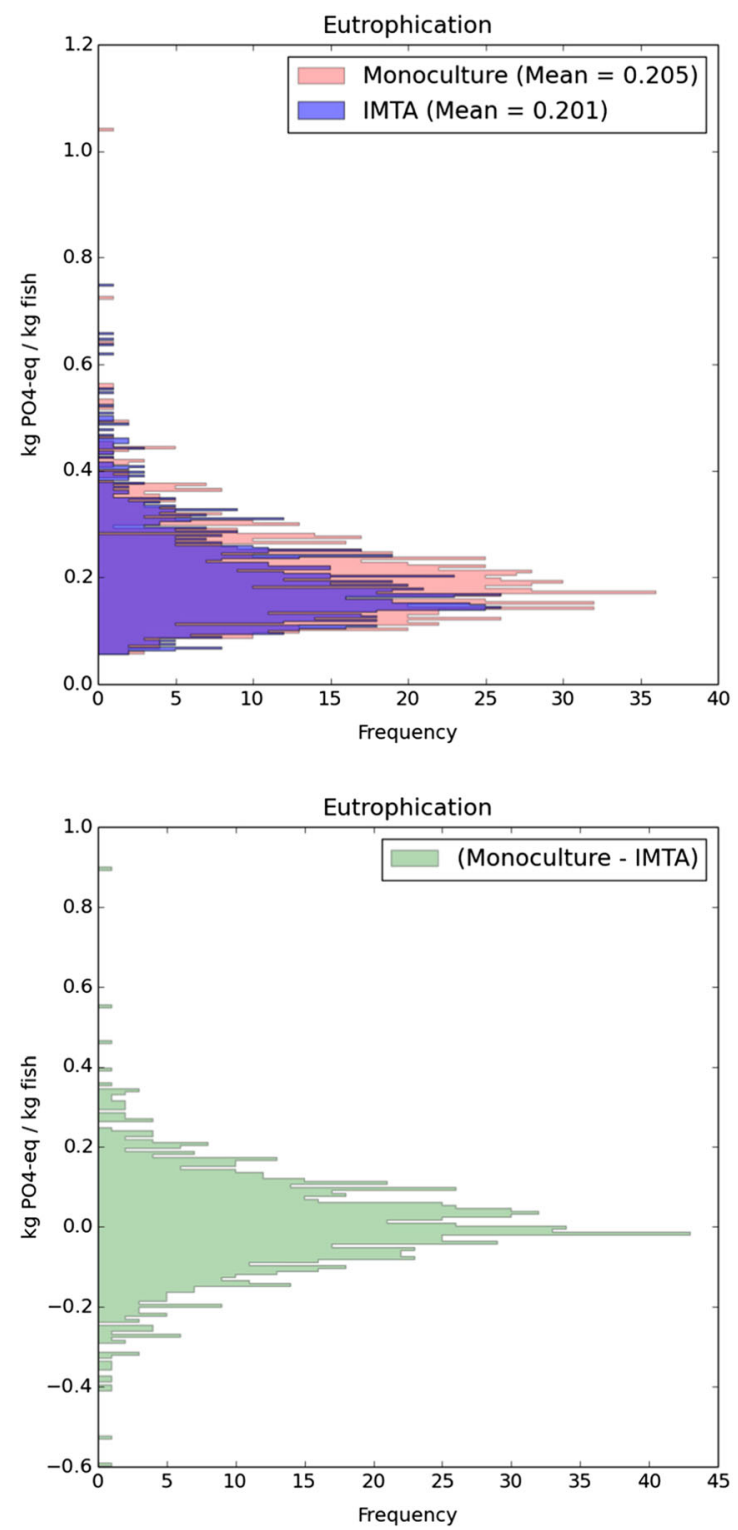

Fig. 3 Top panels display the histogram for $1000 \mathrm{MC}$ runs and 200 bins for eutrophication (top left panel) and climate change (top right panel) for the monoculture and IMTA systems. Bottom panels show the histograms
Fig. 3 show the results for each individual alternative while the bottom panels display the results accounting for relative uncertainties. Moreover, according to Mendoza Beltran et al. (2015), the effect of the choice of allocation method would be visible as peaks (separate peaks for each allocation method) of frequency of results in the top panels. Figure 3 shows only one peak per distribution for both impacts, suggesting that inventory data uncertainty is responsible for most of the uncertainty. This finding is supported by the marginal difference in allocation factors for the allocation methods considered in this case study. To confirm which source of uncertainty in the inputs is responsible of uncertainty in the outcomes, global sensitivity analysis should accompany the method proposed
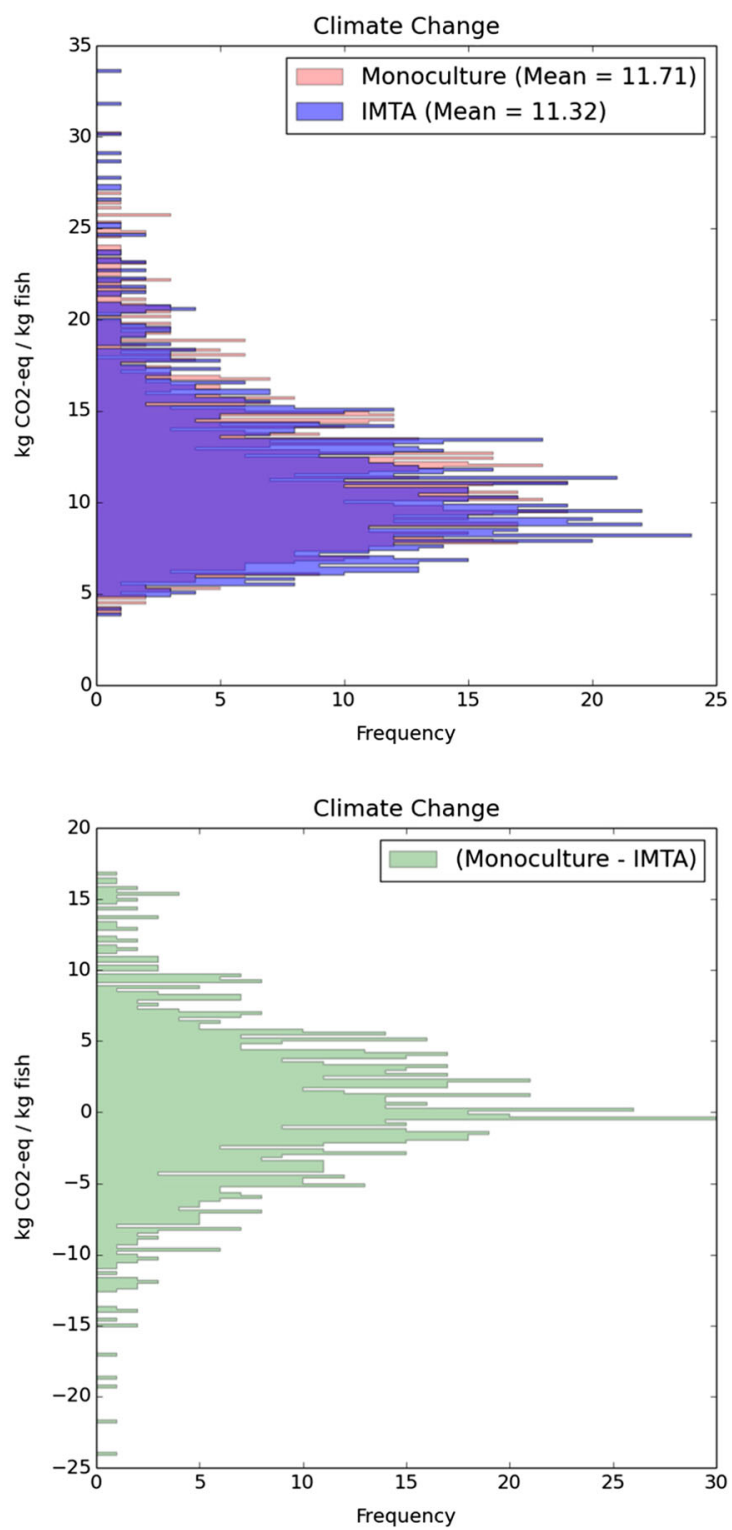

for the difference between monoculture and IMTA per MC run for 1000 $\mathrm{MC}$ runs and 200 bins for eutrophication (bottom left panel) and climate change (bottom right panel) 
here. This is, however, out of the scope of this research and a point for further research.

The lack of significance and differences between both systems can in part be explained by the scale of production of fish/shellfish species. Production of $4 t$ of oysters annually is not small, but remains insignificant in relation to the $240 \mathrm{t}$ of fish produced annually. Therefore, the result is a marginal intensification of the farm's production which in turn leads to approximately equal impacts of the two systems studied. What also must be factored in is the effect of additional environmental impacts originating from activities to construct and manage the IMTA sub-system. These are not visible in the results per se due to the effect of respective production scales. Moreover, as no uncertainty estimates were available for the IMTA sub-system, the effect of the dispersion of these data could not be included. Accounting for it on the oyster add-on would affect the results, as this sub-system corresponds to the differential part between the monoculture and IMTA systems. This quantification remains a question for the future when industrial-scale IMTA systems are established and data uncertainty for all components of the IMTA system becomes available.

Moreover, there is also an integration effect, which refers to the alignment of IMTA processes within the already existing monoculture production processes. These additional processes are essential to determine the magnitude of the impact increase of the IMTA system compared to the monoculture system. For instance, additional fuel use and its associated emissions will largely depend on the synchronization of boat use for maintenance, harvest, and grow-out activities of both fish and oysters, and the difference was not large under the current IMTA system. Moreover, the production, use, and disposal of the add-on infrastructure required for the species added to the site cause additional environmental impacts, the magnitude of which depends on the way in which species integration physically occurs and on the species choice by the farm. In the case study, oyster growth, management, and harvest demanded only a few additional inputs due to the synchrony between tending to both stocks, which could be completed during the normal course of site management activity.

A big challenge for any IMTA system is spatial proximity and temporal synchronization of the species productive cycles. Cranford et al. (2013) have shown that shellfish ability to intercept waste particulates from fish cages diminishes very quickly with distance from the fish site. Also, species considered for IMTA systems have specific growth periods that are not equal and may not overlap to any significant extent. In this study, however, there was a relatively high level of synchronicity. Shellfish were deployed within the existing fish mooring system, and fish were produced over approximately 22 months and oysters for 12 months, and because the oysters came from a hatchery, the farm manager had power over when to deploy the oysters to sea. This is not always the case (Handå et al. 2012) if the IMTA system relies on natural settlement for seed collection (e.g., mussels). In the end, the lack of difference in the impacts of the systems studied in the case study mostly came from differences in production scales between the species. In general, variability between production scales of the species grown in the IMTA system, integration of production in time and space, and the choice of species determine, to a large extent, the trade-offs between implementing monoculture and IMTA systems.

There are some additional impacts that were not included in the current study despite indicators of such impacts being informative of the environmental performance of aquaculture farms. They do not currently correspond to developed LCA impact categories or lack characterization factors. For instance, disease treatment is one activity causing impacts measured by indicators such as the number of disease outbreaks. However, this indicator cannot yet be translated into impacts that are accountable throughout the life cycle of marine offshore aquaculture systems within the LCA methodology (see Rico et al. 2013 for other types of aquaculture), and this is an area where IMTA can have a positive impact (Ford et al. 2012). The presence of shellfish, filtering significant quantities of water to remove particulates, can have beneficial effects in potentially removing parasites, such as sea lice (Chopin et al. 2012), thus reducing infection potential. Moreover, for monoculture and IMTA, there is often a lack of evidence of environmental improvement in the nutrient discharges because of difficulty in directly measuring changes in the environment (Pecorino et al. 2016). This is a major limitation for the proper assessment of the benefits of IMTA in LCA. Water quality around fish farms is intrinsically impacted by the presence of fish farms. However, it is often not measurable because of chemical transformations and mopping up of excess nutrients by other species, such as microalgae. Similarly, although particles are being removed from the water column by the addition of shellfish at the farm, they also produce particulate wastes, so have the potential to increase impacts (Troell and Norberg 1998) or at the very least have no positive change in sediment conditions.

In the case of life cycle impacts such as sea use and biotic resource use (Langlois et al. 2015), the study did not assess these impacts, as data gaps were encountered particularly in background processes such as wild fisheries. Recent work by Avadi et al. (2014) and by Fréon et al. (2014, 2017) on Peruvian anchoveta fishing and reduction, and by SamuelFitwi et al. (2013) and Parker and Tyedmers (2012) for other aquaculture feed ingredients such as Atlantic krill, should be coupled to the assessment of European aquaculture technologies to achieve a good representation of wild fisheries in the supply chain. However, as argued by Henriksson et al. (2015a) and by Heijungs et al. (2017), only relative uncertainties matter for comparative LCAs, and since the feed system remains the same, given that no additional feed is required 
for the oyster growth, these inventory gaps affect the absolute magnitude of the impact but not the comparison itself.

\subsection{Comparative LCAs with uncertainty analysis}

We implemented two methods to quantify, propagate, and interpret results including uncertainties in comparative LCA. The first method relates to simultaneous propagation of inventory data uncertainty and the choice of allocation method (Mendoza Beltran et al. 2015). The second uses relative sampling and statistical testing to interpret the results of the uncertainty analysis (Henriksson et al. 2015a). Simultaneous implementation of these methods tackles two main sources of uncertainty in LCAs in a comparative context and helps interpret the results by means of statistical theory. Allocation methods were applied to foreground processes as they are fundamental in the comparison of monoculture and IMTA systems. We applied partitioning and allocation methods only. It is possible to use the pseudo-statistical propagation with substitution too if data were available (Mendoza Beltran et al. 2015). Combination of these methods increases the conclusions' robustness as the uncertainty due to the allocation choice, together with the uncertainty of inventory data, can be treated from a statistical perspective instead of using one-at-atime scenarios determined by the practitioner. The results showed that using economic allocation or mass partitioning, as in the deterministic LCA, one alternative (IMTA) performs better than the other (monoculture) for all impacts. However, taking into account the two sources of uncertainty and propagating them to the results together with relative sampling showed that there are no statistically significant differences between alternatives for all impacts, except for climate change. Deterministic results lead to oversimplified comparisons and exclude significance information. Therefore, uncertainty results based on the comparative methodology proposed in this study are more robust than deterministic results for comparative LCAs.

An important goal in uncertainty analysis of LCAs should be to treat background processes' multi-functionality, for instance, from the ecoinvent database, in the same way as treating multi-functionality in the foreground processes by taking into account all the possible allocation methods for solving multi-functionality while accounting for inventory data uncertainty too. This study is a step forward in this goal as it shows how to apply a pseudo-statistical propagation method to foreground multi-functional processes of an LCA simultaneously with inventory data uncertainty. Applying the same method to multi-functional background processes would lead to much more robust LCA results because different configurations of the systems on the background would be accounted. For instance, in our case, agricultural processes and wild fisheries could be allocated with multiple methods. This is particularly important as many economies strive towards circularity, where LCA systems will encounter more often multifunctional processes (Mendoza Beltran et al. 2015). Despite some other studies treating uncertainty sources such as methodological choices, modeling assumptions, and inventory data uncertainty, by means of different approaches (Andrianandraina et al. 2015; Gregory et al. 2016), we are not aware of any study so far treating uncertainty due to the choice of allocation method for all multi-functional background processes.

Finally, an important limitation of the method proposed in this study is the management of correlations. We do not account for correlation between inputs and outputs in unit processes. For instance, in our LCA, there is no correlation between fish produced and feed used. This means that the weighted averages and lognormal distributions determine, per MC simulation, how feed use and fish production correlate. This could lead to unrealistic FRCs for the farm under study. This point requires further development. Theories such as the one described by Groen and Heijungs (2017) may constitute a good basis for such further research in this area.

\section{Conclusions}

IMTA is a potentially innovative form of aquaculture in Europe, producing multiple species from different trophic levels within the same location, with lower trophic species utilizing the wastes from the higher trophic species, thus encouraging reuse of materials. In this sense, it is regarded as an environmentally beneficial form of aquaculture farming in comparison to traditional monoculture. This study implemented a comparative LCA with uncertainty analysis to understand the trade-offs between IMTA and monoculture fish production for a specific SME and concluded that the integration of fish and oyster culture led to marginal environmental benefits in comparison with the monoculture operation to produce fish. We found that the choice of allocation method had an influence on the magnitude of the benefits of IMTA production of fish. However, calculation of the same impacts including relative uncertainties due to inventory data and due to the choice of allocation method showed that there was no significant difference between the impacts of the systems, primarily due to the different scales of production between the two species. An increase in oyster seeding volume may well provide a more robust statistically provable benefit.

Moreover, statistical significance of the difference of the impacts between both systems could be determined because relative uncertainties were taken into account. Thus, processes that were common to both systems were sampled using the same inventory data values and 
allocation method choice as well as the difference per MC run was calculated for the characterized results. Failing to use such an experimental setup would lead to LCA results that cannot be used as a base to establish statistical significance and should not be compared. Despite succeeding in the application of this comparative methodology including various uncertainties, what would be more useful is to apply it to a significantly larger, fully industrialized IMTA system or at a bay scale. Such scale, where the totality of production of different species is considered as a broad-scale IMTA system, thus individual farm integration is less relevant, and where uncertainty estimates are available for the IMTA sub-system inventory data, would provide more robust conclusions about the environmental benefits of this type of aquaculture in Europe and elsewhere.

Moreover, to explain the output variability in terms of the input variability or to identify whether uncertainty due to methodological choices or inventory data uncertainty are responsible for uncertainty in the outcomes, the method applied here would have to be combined with global sensitivity analysis. Nonetheless, it was shown that for our case, most uncertainty in the results is probably due to inventory data dispersion and not due to the choice of allocation method, particularly given the small differences in the allocation factors for the allocation methods considered.

This case study provided a useful means to test a novel method of dealing with two major sources of uncertainty in LCA, namely inventory data and allocation choice. Both play a key role in determining the impacts of monoculture and IMTA fish production. When not accounting for uncertainties (deterministic LCA results), IMTA was the best performing option for all impacts considered here, and when accounting for uncertainties, both options performed statistically equal for all impacts, except climate change. The comparative methodology including various uncertainties used here is a novel technique that can contribute to the robustness of conclusions as it adds information about the significance of results in a comparison between technologies, fish production in this case. Further research is required to extend this method to include other sources of uncertainty as well as other allocation choices, including, for example, substitution or system expansion. Further research is also required to more fully treat background multi-functional processes as was done with foreground multi-functional processes in this study and include correlations where relevant.

Acknowledgements This research has been completed as part of the IDREEM project (Increasing Industrial Resource Efficiency in European Mariculture (www.idreem.eu) and has received funding from the European Union's Seventh Framework Program (FP7/2007-2013) under grant agreement no. 308571. The authors would also like to thank the insightful comments of Professor Arnold Tukker as well as those of Glenn Aguilar Hernandez and three anonymous reviewers.
Finally, we would like to thank the valuable help of Shreya Ganeshan with the revision and compilation of relevant literature.

Open Access This article is distributed under the terms of the Creative Commons Attribution 4.0 International License (http:// creativecommons.org/licenses/by/4.0/), which permits unrestricted use, distribution, and reproduction in any medium, provided you give appropriate credit to the original author(s) and the source, provide a link to the Creative Commons license, and indicate if changes were made.

\section{References}

Abreu MH, Varela DA, Henríquez L et al (2009) Traditional vs. integrated multi-trophic aquaculture of Gracilaria chilensis. In: Bird CJ, McLachlan J, Oliveira EC (eds) Productivity and physiological performance. Aquaculture 293:211-220

Agresti A, Franklin CA (2007) Statistics - the art and science of learning from data. Prentice Hall, Inc., Upper Saddle River

Amano K, Ebihara M (2005) Eco-intensity analysis as sustainability indicators related to energy and material flow. Manag Environ Qual An Int J 16:160-166

Andrianandraina VA, Senga Kiessé T et al (2015) Sensitivity analysis of environmental process modeling in a life cycle context: a case study of hemp crop production. J Ind Ecol 19:978-992

Avadi A, Freon P, Tam J (2014) Coupled ecosystem/supply chain modelling of fish products from sea to shelf: the Peruvian anchoveta case. PLoS One. doi:10.1371/journal.pone.0102057

Björklund AE (2002) Survey of approaches to improve reliability in LCA. Int J Life Cycle Assess 7:64-72

Buschmann AH, Troell M, Kautsky N (2001) Integrated algal farming: a review. Cah Biol Mar 42:83-90

Chopin T, Buschmann AH, Halling C et al (2001) Integrating seaweeds into marine aquaculture systems: a key toward sustainability. J Phycol 986:975-986

Chopin T, Yarish C, Sharp G (2007) Beyond the monospecific approach to animal aquaculture - the light of integrated multi-trophic aquaculture. In: Ecological and genetic implications of aquaculture activities methods and technologies in fish biology and fisheries. pp $447-458$

Chopin T, Cooper JA, Reid G et al (2012) Open-water integrated multitrophic aquaculture: environmental biomitigation and economic diversification of fed aquaculture by extractive aquaculture. Rev Aquac 4:209-220

CML-Department of Industrial Ecology (2016) CML-IA characterisation factors. https://www.universiteitleiden.nl/en/research/researchoutput/science/cml-ia-characterisation-factors\#downloads

Cranford PJ, Reid GK, Robinson SMC (2013) Open water integrated multi-trophic aquaculture: constraints on the effectiveness of mussels as an organic extractive component. Aquac Environ Interact 4: $163-173$

Cubillo AM, Ferreira JG, Robinson SMC et al (2016) Role of deposit feeders in integrated multi-trophic aquaculture - a model analysis. Aquaculture 453:54-66

Czyrnek-Delêtre MM, Rocca S, Agostini A et al (2017) Life cycle assessment of seaweed biomethane, generated from seaweed sourced from integrated multi-trophic aquaculture in temperate oceanic climates. Appl Energy 196:34-50

Ferreira JG, Saurel C, Ferreira JM (2012) Cultivation of gilthead bream in monoculture and integrated multi-trophic aquaculture. Analysis of production and environmental effects by means of the FARM model. Aquaculture 358-359:23-34 
Ford JS, Pelletier NL, Ziegler F et al (2012) Proposed local ecological impact categories and indicators for life cycle assessment of aquaculture. J Ind Ecol 16:254-265

Fréon P, Avadí A, Vinatea Chavez RA, Iriarte Ahón F (2014) Life cycle assessment of the Peruvian industrial anchoveta fleet: boundary setting in life cycle inventory analyses of complex and plural means of production. Int J Life Cycle Assess 19: $1068-1086$

Fréon P, Durand H, Avadí A et al (2017) Life cycle assessment of three Peruvian fishmeal plants: toward a cleaner production. J Clean Prod 145:50-63

Frischknecht R, Jungbluth N, Hans-Jörg A et al (2007) Overview and methodology - ecoinvent report No. 1. Dübendorf

Granada L, Sousa N, Lopes S, Lemos MFL (2015) Is integrated multitrophic aquaculture the solution to the sectors' major challenges? A review. Rev Aquac 283-300

Gregory J, Noshadravan A, Olivetti E, Kirchain R (2016) A methodology for robust comparative life cycle assessments incorporating uncertainty. Environ Sci Technol 50:6397-6405

Groen EA, Heijungs R (2017) Ignoring correlation in uncertainty and sensitivity analysis in life cycle assessment: what is the risk? Environ Impact Assess Rev 62:98-109

Handå A, Min H, Wang X et al (2012) Incorporation of fish feed and growth of blue mussels (Mytilus edulis) in close proximity to salmon (Salmo salar) aquaculture: implications for integrated multi-trophic aquaculture in Norwegian coastal waters. Aquaculture 356-357: $328-341$

Heijungs R, Frischknecht R (2005) Representing statistical distributions for uncertain parameters in LCA. Int J Life Cycle Assess 10:248254

Heijungs R, Kleijn R (2001) Numerical approaches towards life cycle interpretation five examples. Int J Life Cycle Assess 6:141-148

Heijungs R, Henriksson P, Guinée J (2016) Measures of difference and significance in the era of computer simulations, meta-analysis, and big data. Entropy 18:361

Heijungs R, Henriksson PJG, Guinée JB (2017) Pre-calculated LCI systems with uncertainties cannot be used in comparative LCA. Int J Life Cycle Assess 22:461

Henriksson PJG, Guinée JB, Kleijn R, de Snoo GR (2012) Life cycle assessment of aquaculture systems - a review of methodologies. Int J Life Cycle Assess 17:304-313

Henriksson PJG, Guinée JB, Heijungs R et al (2014) A protocol for horizontal averaging of unit process data - including estimates for uncertainty. Int J Life Cycle Assess 19:429-436

Henriksson PJG, Heijungs R, Dao HM et al (2015a) Product carbon footprints and their uncertainties in comparative decision contexts. PLoS One 10:e121221

Henriksson PJG, Rico A, Zhang W et al (2015b) Comparison of Asian aquaculture products by use of statistically supported life cycle assessment. Environ Sci Technol 49:14176-14183

Hughes A, Black K (2016) Going beyond the search for solutions: understanding trade-offs in European integrated multi-trophic aquaculture development. Aquac Environ Interact 8:191-199

ISO (2006) ISO 14044. Environmental management-life cycle assessment-requirements and guidelines. Switzerland

Klinger D, Naylor R (2012) Searching for solutions in aquaculture: charting a sustainable course. Annu Rev Environ Resour 37:247276

Langlois J, Fréon P, Steyer J-P et al (2015) Sea use impact category in life cycle assessment: characterization factors for life support functions. Int J Life Cycle Assess 20:970-981

Mekonnen MM, Hoekstra AY (2011) The green, blue and grey water footprint of crops and derived crop products. Hydrol Earth Syst Sci 15:1577-1600
Mendoza Beltran A, Heijungs R, Guinée J, Tukker A (2015) A pseudostatistical approach to treat choice uncertainty: the example of partitioning allocation methods. Int J Life Cycle Assess 21:252-264

Mendoza Beltran A, Prado-lopez V, Font Vivanco D et al (2017) Quantified uncertainties in comparative LCAs: what can be concluded? Environ Sci Technol. Submitted

Neori A, Chopin T, Troell M et al (2004) Integrated aquaculture: rationale, evolution and state of the art emphasizing seaweed biofiltration in modern mariculture. Aquaculture 231:361-391. doi:10.1016/j. aquaculture.2003.11.015

Parker RWR, Tyedmers PH (2012) Life cycle environmental impacts of three products derived from wild-caught Antarctic krill (Euphausia superba). Environ Sci Technol 46:4958-4965

Pecorino D, Povero P, Olivari E, Chiantore M (2016) A European scale comparison of off-shore mariculture farms shows good environmental sustainability and scope for growth. In: Proceedings of Aquaculture Europe

Pelletier N, Tyedmers P (2008) Life cycle considerations for improving sustainability assessments in seafood awareness campaigns. Environ Manag 42:918-931

Prado-Lopez V, Wender BA, Seager TP et al (2016) Tradeoff evaluation improves a photovoltaic case study. J Ind Ecol 20:710-718

Price CS, Morris JJ (2013) Marine cage culture and the environment twenty-first century science informing a sustainable industry. NOAA Technical Memorandum NOS NCCOS 164, 158 pp

Reid GK, Liutkus M, Robinson SMC et al (2009) A review of the biophysical properties of salmonid faeces: implications for aquaculture waste dispersal models and integrated multi-trophic aquaculture. Aquac Res 40:257-273

Reid GK, Robinson SMC, Chopin T et al (2013) Dietary proportion of fish culture solids required by shellfish to reduce the net organic load in open-water integrated multi-trophic aquaculture: a scoping exercise with cocultured Atlantic salmon ( Salmo salar ) and blue mussel ( Mytilus edulis ). J Shellfish Res 32:509-517

Rico A, Geng Y, Focks A, Van den Brink PJ (2013) Modeling environmental and human health risks of veterinary medicinal products applied in pond aquaculture. Environ Toxicol Chem 32:1196-1207

Rosenbaum RK, Bachmann TM, Gold LS et al (2008) USEtox- the UNEP-SETAC toxicity model: recommended characterisation factors for human toxicity and freshwater ecotoxicity in life cycle impact assessment. Int J Life Cycle Assess 13:532-546

Samuel-Fitwi B, Meyer S, Reckmann K et al (2013) Aspiring for environmentally conscious aquafeed: comparative LCA of aquafeed manufacturing using different protein sources. J Clean Prod 52: 225-233

Swiss Centre For Life Cycle Inventories (2007) Ecoinvent Database 2.2. Ecoinvent Cent. 2.0

Troell M, Norberg J (1998) Modelling output and retention of suspended solids in an integrated salmon-mussel culture. Ecol Model 110:6577

Troell M, Halling C, Neori A et al (2003) Integrated mariculture: asking the right questions. Aquaculture 226:69-90

UNEP/SETAC Life Cycle Initiative (2004) Declaration of Apeldoorn on LCIA of Non-Ferrous Metals. pp 1-2

Vázquez-Rowe I, Hospido A, Moreira MT, Feijoo G (2012) Best practices in life cycle assessment implementation in fisheries. Improving and broadening environmental assessment for seafood production systems. Trends Food Sci Technol 28:116-131

Weidema B, Wesnæs M (1996) Data quality management for life cycle inventories - an example of using data quality indicators. J Clean Prod 4:167-174

Ziegler F, Hornborg S, Green BS et al (2016) Expanding the concept of sustainable seafood using life cycle assessment. Fish Fish 17:10731093 